\title{
The Impact Of Technology In Teaching Freshman Economics: A Quantitative Approach
}

Kenneth J. Sousa, (E-mail: ksousa@bryant.edu), Bryant University Sam Mirmirani, (E-mail: smirmira@bryant.edu), Bryant University

\begin{abstract}
This paper uses a quantitative approach to determine the relationship, if any, among the use of information technology in a freshman economics lecture environment. Over a two-semester period, students in four sections of economics courses were used as treatment and control groups. These classes consisted of two sections each of microeconomics and macroeconomics. The content for each course was delivered using several examples of technology (treatment) and conventional methods (control). At the end of each class session, students were asked to complete a survey to measure their perceptions of the lecture. The survey measured their perceptions of retention, ability to understand the material, testing confidence and other components, which would increase/decrease the understanding of the material. After analyzing the survey data, there were clear relationships among the use of technology and understanding the lecture material. The results suggested that certain attributes of technology (color, character composition, graphing) provided a positive experience for the student. However, some components of technology methods showed little effect on the learning process. Specifically, students did not perceive the use of multimedia as having a significant effect on the retention or understanding process.
\end{abstract}

\section{INTRODUCTION}

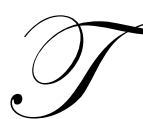

he core of the education industry - synergetic relationships between teachers and students and the educational tools, such as books and periodicals - has been challenged by the wave of information technology. Of course, various disciplines have responded to this wave differently. Some disciplines, such as the Sciences, are far ahead while the Social Sciences are still trying to catch up.

Recently, there has been a decline in students' interest in selecting Economics as a concentration. This trend is due, in part, to the perception that Economics concentration relies on "chalk and talk" instruction methods. Therefore, a modification in instruction methodologies could potentially reverse this trend, as suggested by Becker and Watts (1996). In a case study, Georgiou (2005) makes an assessment of the role of Economics Major at institutions with undergraduate business programs. It is pointed out that while the number of Economics Major is "declining," in general, economics courses are more populated by students. This is due to the fact that more non-majors are taking economics classes.

Regardless of their respective position, in the race of technology adaptation, an important consideration is the impact of integrating information technology in the classroom and quantifying how such technologies are improving the quality of instruction. Our objective is to assess the impact of incorporating technological components, such as PowerPoint presentations and the Internet, in freshman Economics classes compared to a conventional method of instruction i.e. lecture-based teaching. Through surveys, we measured students' responses and assessed the significance of these tools in the learning process. The organization of the paper is as follows. First, a review of the literature is provided. Next, an explanation of the current environment is given. This section is followed by the methodology and data analysis. Finally, the conclusion and future research potentials are. 


\section{LITERATURE REVIEW}

Technological progress in the education industry has changed the role of educators by bringing a new dimension to the art of teaching in the classroom. Educators of the $21^{\text {st }}$ Century are evolving from instructors to facilitators, as mentioned in Greenhalgh (1997). Among the many advantages of using technology in the classroom, McGrath (1998) points out that technology: Increases student's motivation for learning, promotes cooperation among students and teachers, encourages students to be more interested in problem solving, brings more "real world" situations to the classroom, and provides opportunities for interdisciplinary exploration. Utilizing technology in the classroom enhances students' learning by creating a mental structure that can synthesize information more effectively. This assertion is supported in Bosco (1994). The new generation in higher education institutions is motivated by a different mode of instruction delivery. Members of "Generation X", whom are already at the college age, are being replaced by "Generation Next". Wellner (1999) suggests that the "Next" generation, with "high-tech saturation", will have major implications for educators. Textbook and conventional lecturing methods alone, may not be sufficient to motivate students and enhance their learning process.

Kilpatrick (1998) extends the boundaries of educational tools to include new technology. He asserts that conventional tools of learning, such as books, will become a "popular entertainment device" and will lose their appeal as a "serious tool for learning." Stone (1999), in reference to multimedia technology, explains that this technology is "one piece" of teaching that consists of many elements. He concludes that this technology tends "to make learning interesting and entertaining." Similar conclusions relating to the use of multimedia were drawn by Kydd (1999). She concludes that students may not focus on the lecture material because the pictures in the presentation distract them.

Any major change in the direction of the education system is obviously resisted on many grounds. One aspect of such resistance is related to the role change of the teacher, as explained above. In the advent of technology-based instruction, the teacher cannot be fully in charge and authority is shifted from the instructor to the technology developer. In a report, Allen (1997) compares the changes in the education industry to the health care industry and the growth of managed care. In that environment, doctors are losing their control over patients and cannot independently make decisions regarding their patients' diagnosis.

Recently, the impact of Internet technology has been evaluated and researched by Agarwal and Day (1998). Their research shows an enhancement of communication among the student. They conclude that Internet technology has a positive influence on standardized test and final grades, as well as, the student's perception of instructor effectiveness.

In an analysis using PowerPoint and Internet in macro principles, Parks (1999) evaluated the positive and negative sides of these two technologies. Based on comments from students, he suggested that PowerPoint technology "must be used along with blackboard." Furthermore, Parks (1999) concluded that, Internet technology, with its electronic mail and communication features, enhanced the learning process. The same conclusion is derived in Manning (1996) with a focus on education in Economics. Web technology, as a communication device, is also found to be an effective means of assisting students in learning coursework developed by Economics instructors (Daniel 1999). Chimer and Walbert (1999) use Web technology as an integral part of delivering instruction in Statistics, Econometrics and Microeconomic theory courses. They assert that "good teaching practice" should take advantage of Web technology. Availability of internet technology at a reasonable cost allows distance-based education without compromising quality and effectiveness of instructions (Raymond, 2000).

With a cross section of 30 Economics instructors at 15 institutions, Sosin, et. al (2004) investigate the impact of technology on student performance in freshman Economics classes. They found that the use of technology has a "small, but positive" effect. The integration of technology, alone, does not provide significant benefits to the learning process -active participation is an essential component. This point is supported by Simkins (1999), who suggests that these technologies "improve cognitive learning and generate broader student interest in economics." 


\section{EVOLUTION OF INTEGRATION}

In an attempt to gain insight on the history of this issue, we discovered a limited amount of research. Various hypotheses, however, regarding the effectiveness of integrating technology in the classroom have been explored. Some researchers have argued that the lack of demand for computer-aided instruction materials is due to the limited information about their effectiveness (Porter, 1992). Therefore, most of the publications presented subjective conclusions on the use of technology for the Economics discipline.

As technology was making an impact in business education in the late 1980s, an education in Economics was lagging behind other disciplines with respect to the use of Information Technology in the classroom (Katz and Becker, 1999). Science and business disciplines were achieving more success in this area. The direct use of computers to assist the instruction process, using CAI software, was not utilized by the Economics discipline until just recently. Katz (1999) and Daniel (1999) integrated CAI in their classroom and achieved a positive impact on student's learning of economics.

However, several questions must be asked regarding the use of technology in an Economics education. In each case, can the influence of technology:

- $\quad$...provide any measurable impact on the retention of material?

- $\quad$...modify the student's level of interest in Economics?

- $\quad$...introduce a more successful paradigm to deliver the material?

- $\quad$...build a more effective learning environment illustrating graphical and transitional information?

- $\quad$...impact the effectiveness of the instructor's lecture?

- $\quad$...inhibit the flexibility related to the delivery of the lecture material?

\section{LECTURE AND SURVEY INTEGRATION}

Four sections of Economics courses assigned to one professor were utilized to conduct the research. Specifically, two sections of Macroeconomics and Microeconomics were selected as the population sample. These freshman-level courses were required for all Undergraduate students majoring in Business. These sections included students from a variety of disciplines as well as undeclared disciplines.

To complete this research, three components were designed: 1) Survey, 2) Survey/delivery schedule and 3) Technology components. The basis of the research was to quantify the student's perception in the areas of material clarity and retention and interest, as it relates to the delivery method of the economics material during the scheduled classroom session. In order to achieve this, it would be necessary to provide a baseline for each class. This would involve the delivery of the material in a conventional manner (traditional lecture). Therefore, a schedule for each class was compiled to alternate the delivery methods (conventional and technology) over an eight-week period. A survey question was developed to independently measure the two delivery methods. At the end of each class, the survey was distributed to measure the perceptions of the lecture based on the scheduled method.

The survey consisted of ten questions attempting to probe students for perceptions and reactions to the environment experienced during the class period. The immediacy of the survey administration provided timely recollection and assessment of the lecture experience. Also, the repetition of alternating methods and the subsequent survey allowed the capture of time-based information for trending, comparison and sample size. Respondents were asked to select a response for each question in the survey. A Likert scale of five options was used to measure each question: Agree Strongly, Agree Basically, No Opinion, Disagree Basically and Disagree Strongly. The survey questions are outlined in Appendix A.

The technology tools utilized for classroom lectures included PointCast and PowerPoint slide presentation packages. For the purposes of completing this initial research, simplicity was the focus of the technology tools. 
Therefore, the results and perceptions on the initial use of technology would include a limited number of variables and complexity.

\section{SELECTION AND EVALUATION OF TECHNOLOGY TOOLS}

An important facet of this research was the effect on the instructor's delivery and preparation for the course. The subjective perceptions of the instructor, whether positive or negative, would ultimately affect the interest and the level (what kind of level? Difficulty level? Or Interest Level?) of information delivered. Course preparation time, complexity of technology utilized, level of integration required, and ease of use, are all important factors to balance when considering the integration of technology in the classroom. The dynamic level of human interaction in classroom lectures can easily affect the level of retention and interest in the classroom material. Therefore, the instructor needs to be comfortable with the use and placement of technology within the lecture sessions. As the level of comfort increases, the technology will become a seamless addition to the lecture delivery.

PointCast is a PC-based client that utilizes Web-based "push" technology. Using the Internet, it compiles over 700 sources of worldwide information into a central repository to broadcast directly to its subscribers. Throughout the day, PointCast continually updates its news, financial and information sources. Based on the frequency selected by the subscriber (e.g. hourly, daily, manually), PointCast information is delivered directly to the subscriber's desktop computer system via the Internet. Channels, selected by the individual subscriber, determine the information received at the local desktop.

The slide presentation package, included with the text, provide a foundation of text and graphical material used for the lectures. There are many benefits to utilizing this technology over the conventional "chalk and talk" method:

- A pre-defined, sequential order of lecture material. The professor can provide a layout and sequence of the topics necessary for a lecture. Topics can be inserted, deleted and moved as necessary.

- Consistent - The issues, concepts and definitions can be delivered without accidental omission. As a natural extension of the text, facts and concepts outlined in the package can be relied upon for all deliveries of the course.

- Graphical Representation - Many of the topics and issues reviewed in a classroom lecture are visual in nature. Without the ability to create analogies and comparisons using these graphics, the student's retention and understanding are compromised. While these visual components are included in the text, it is difficult for the instructor and student to "connect" without having a common object of focus.

- $\quad$ Flexibility - The delivery of specific slides can be altered based on questions from students and the dynamic of the class. With minimal disruption, a concept or issue could be viewed for reinforcement or reference.

The PointCast software was installed, both in faculty offices, as well as, the classrooms equipped with an overhead projection device. Several channels were selected for subscription using PointCast. The channels were selected for their content relating to daily business and economic news broadcasts. Specifically, four channels were selected for classroom discussion: The Washington Post, The Wall Street Journal, The Boston Globe and The New York Times.

News stories and articles provided through the selected channels were scanned prior to each class. Items that related to the lecture topic were noted. This preview provided the opportunity to filter appropriate information for presentation during the lecture as well as any thoughts to focus a short classroom discussion.

The availability of this timely information provided the opportunity to relate "real world" information to students. Reviewing a current news story, legitimized course topics and issues. It extended the boundaries of the course material beyond the textbook to the world of business, while building interest in economic concepts. In addition, the use of PointCast subtly teaches the importance of remaining current in daily business issues. 
PointCast information allowed the integration of timely business topics and news issues into the lecture of the class. The immediacy in showing students the various news and business issues in an on-line, interactive manner, provided a valuable experience for students. The students were able to view the PointCast interface, directly, during class time and enabled students to familiarize themselves with the current business and economic events of the day.

\section{METHODOLOGY AND RESULTS}

The test conducted for the sample survey is multivariate analysis of variance known as MANOVA. This is a powerful technique that is commonly used in survey-based research studies. MANOVA is a flexible method and allows researchers to assess overall differences among various groups of independent variables and maintain statistical efficiencies. It requires a minimum of 20 observations for each group of independent variables. In this study, the number of observations for the Microeconomics and the Macroeconomics were 441 and 414, respectively. For the test on instructional technique (i.e. conventional vs. technology), the sample size was 431 and 424 , respectively. Imposing a general linear model, all values were significant - at 95\% or higher, as shown in Table 2 in Appendix B.

Table 2 focuses on the methods of instruction in which the sample size of both Microeconomics and Macroeconomics are combined. The only measure in this Table that was not statistically significant was the question on the use of multimedia, sound and video to transfer information (Question 7d). This may be the result of a lack of clarity in definition regarding multimedia, particularly in the survey on the conventional method of instructions. We believe that this outcome may have been caused by the lack of multimedia components in the technology-based lecture materials. Therefore, students may not have been able to establish a point of reference to compare the effect of multimedia use during the classroom lectures versus a conventional method.

With the exception of Question 2, this Table also reveals that, overall; technology had a higher mean score than the conventional method. This suggests that students basically agreed with the premise that technology-based lectures were helpful in the learning process. From the survey results, specific survey components in which technology was used scored higher (mean value of 4 and above) than others. These results were due to the technology's specific attributes (the ability to view graphs, the use of color and characters, and the use of simulation to illustrate changes in economic situations); and the ease in following the lecture.

In reviewing the mean scores associated with technology-based lectures, it was discovered that the largest mean scores were associated with questions $7 \mathrm{a}, 7 \mathrm{~b}$ and $7 \mathrm{c}$. These questions were designed to gather information relating to the visual effect of technology-based lectures, graphics, text attributes and simulations. We believe that this outcome further affirms the fact that this generation of students is more visually-oriented. Therefore, it is our contention that the integration of visual components tends to enhance the learning experience in Economics.

One may argue that pre-packaged lectures compiled through technology may be too rigid and, therefore, impede creativity and the instructor's ability to tailor material to suit the needs of individual classes. Survey Question \#2 attempted to determine the magnitude of this issue. For this purpose, the survey question was designed to address the issue in the form of a negative question. For example in a technology survey, a student response of " 2 " (Basically Disagree) would translate to "the inability to deviate from the technology-based lecture did not hinder my comprehension of the subject matter." Therefore, the survey results indicate that flexibility is not compromised when integrating technology into the delivery of lecture material.

\section{SUMMARY AND CONCLUSIONS}

Although the education industry appears to lag behind business organizations in the integration of technology, educators have been motivated to redesign the method of instruction for educating students in a dynamic environment. The rapid expansion and availability of technology has provided the tools necessary to transition this redesign process into a workable and effective solution. 
Economics education has not sufficiently benefited from the advantages of technology integration as compared to other disciplines. Decline in overall enrollment in economics has concerned the American Economic Association (AEA). As part of their policy, AEA has been expanding their Teachers Training Program (TEP). New instructional technologies and pedagogies are now an integral part of the TEP (Knoedler and Underwood, 2003). Furthermore, quantitative analysis with respect to the impact of contemporary instructional methods in the Economics discipline has been fairly limited. The use of technology can provide students with increased retention, interest and inter-disciplinary applications. In the absence of an objective assessment on the use of technology, these contemporary methods may not only diminish the benefits outlined in our research, but also hinder their interest in an Economics education. Therefore, our purpose was to capture the perceptions regarding particular delivery methods through a survey technique.

The survey results suggest that when compared with conventional instruction method, technology-based delivery did, in fact, provide a more positive learning environment. Notably, students perceived the presentation and visual-effect attributes of technology delivery, had a greater influence in the learning process.

Future research would be useful to determine the impact, if any, on the use of technology specific to Microeconomics and Macroeconomics courses. This analysis will provide insight into the level of integration specific to the concepts and material of these courses. "Do specific concepts and topics benefit more from the integration of technology?"

In addition, a further expansion of this quantitative research could potentially focus on the impact on graduate-level economics courses. Is technology more effective in a graduate-level course? Do graduate students perceive this lecture environment more positively than undergraduate students?

One of the issues in our research was related to the use of multimedia software during classroom lectures. The availability of enhanced multimedia components with Economics textbooks can increase the potential integration of this technology in future classes. Therefore, the multimedia survey question (7d) that attempts to quantify its impact can be analyzed more accurately. However, the measurement of such impact is not statistically significant.

\section{APPENDIX A}

\section{Technology-based Lecture Survey}

1. I completely understood the topic material.

2. (T) The inability to deviate from the technology-based lecture hindered my comprehension of the subject covered.

(C) The ability to deviate from the lecture by raising question(s) from the instructor helped to comprehend the subject covered.

3. (T) I found the technology easy to follow through the progression of the lecture material.

(C) I found it easy to follow the progression of the lecture material.

4. I could explain the topic to others well.

5. I I believe that I will do well when I am tested on this topic.

6. (T) The integration of the technology helped significantly.

(C) This material would be better understood with the integration of technology.

(T) What technology attributes provided a better understanding of the lecture material?

(C) What technology attributes would provide a better understanding of the lecture material?

7a. $\quad \ldots$ Graphs?

7b. ... Color and character attributes for highlighting purposes?

7c. $\quad \ldots$ Simulating changes to describe economic situations?

7d. ... Use of multimedia, sound and video to transfer information?

(C) Conventional Survey; (T) Technology Survey 


\section{APPENDIX B}

Table 1 - Multivariate Test Results for Instructional Method

\begin{tabular}{|l|c|c|c|}
\hline & Error df & Significance & Eta Squared \\
\hline Pillai's Trace & 842.000 & .000 & .149 \\
\hline Wilks' Lambda & 842.000 & .000 & .149 \\
\hline Hotelling's Trace & 842.000 & .000 & .149 \\
\hline Roy's Largest Root & 842.000 & .000 & .149 \\
\hline
\end{tabular}

Table 2 - Tests Between-Subject Effects for Instructional Method

\begin{tabular}{|c|l|c|c|c|}
\hline Question \# & Dependent Variable & F Value & Significance & Eta Squared \\
\hline 1 & Understood Topic & 5.745 & .017 & .007 \\
\hline 2 & Deviate From Lecture & 79.547 & .000 & .085 \\
\hline 3 & Easy To Follow Progression & 22.716 & .000 & .026 \\
\hline 4 & Explain Topic Well & 5.823 & .016 & .007 \\
\hline 5 & Test Well & 13.143 & .000 & .015 \\
\hline 6 & Technology Assist w/Lecture & 20.259 & .000 & .023 \\
\hline $7 \mathrm{a}$ & Graphs & 23.992 & .000 & .027 \\
\hline $7 \mathrm{~b}$ & Text Attributes & 27.063 & .000 & .031 \\
\hline $7 \mathrm{c}$ & Simulation & 6.839 & .009 & .008 \\
\hline $7 \mathrm{~d}$ & Multimedia & 2.441 & .119 & .003 \\
\hline
\end{tabular}

Table 3 - Mean Scores by Survey Question

\begin{tabular}{|c|l|c|c|c|c|}
\hline \multicolumn{2}{|c|}{ Dependent Variables } & \multicolumn{2}{c|}{ Conventional } & \multicolumn{2}{c|}{ Technology } \\
\hline Question \# & \multicolumn{1}{|c|}{ Question Description } & Mean & Std. Error & Mean & Std. Error \\
\hline 1 & Understood Topic & 3.849 & 0.041 & 3.988 & 0.041 \\
\hline 2 & Deviate From Lecture & 3.552 & 0.051 & 2.908 & 0.051 \\
\hline 3 & Easy To Follow Progression & 3.697 & 0.046 & 4.009 & 0.047 \\
\hline 4 & Explain Topic Well & 3.314 & 0.050 & 3.486 & 0.051 \\
\hline 5 & Test Well & 3.381 & 0.047 & 3.625 & 0.048 \\
\hline 6 & Technology Assist w/Lecture & 3.614 & 0.046 & 3.907 & 0.046 \\
\hline $7 \mathrm{a}$ & Graphs & 3.950 & 0.042 & 4.240 & 0.042 \\
\hline $7 \mathrm{~b}$ & Text Attributes & 3.783 & 0.044 & 4.110 & 0.045 \\
\hline $7 \mathrm{c}$ & Simulation & 3.861 & 0.043 & 4.020 & 0.043 \\
\hline $7 \mathrm{~d}$ & Multimedia & 3.584 & 0.049 & 3.692 & 0.049 \\
\hline
\end{tabular}

\section{REFERENCES}

1. Agarwal, R. and A. E. Day. 1998. The impact of the internet on economic education. Journal of Economic Education 30 (Spring): 99-110.

2. Allen, C. 1997. The virtual university. Washington Post. August 10.

3. Becker, W. E., and M. Watts. 1996. Chalk and talk: a national survey on teaching undergraduate economics. American Economic Review, Papers and Proceedings 86 (2): 448-453.

4. Bosco, J. 1994. Schooling and learning in an information society. OTA, Contractor Report (November): NTIS No. 95-172227.

5. Chimer, J. F. and M. S. Walbert. 1999. Web-based learning environments guided by principles of good teaching practice. Journal of Economic Education (Summer): 248-259 
6. Daniel, J. I. 1999. Computer-aided instruction on the world wide web: the third generation. Journal of Economic Education (Spring): 163-174.

7. 1999. Using the Web to Improve Computer-Aided-Instruction in Economics. Journal of Economic Education (Summer): 225-243.

8. Georgiou, G. C. 2005. Economics and Business: David vs. Goliath at Undergraduate Business Schools. Proceedings, The 2005 College Teaching and Learning Conference, Clute Institute for Academic Research, (March): ISSN 1539-8757.

9. Greenhalgh, J.B. 1997. Using the internet: concept to classroom. T.H.E Journal Supplement (May): 15-19.

10. Katz, A. 1999. A computer-aided exercise for checking novices' understanding of market equilibrium changes. Journal of Economic Education (Spring): 148-162.

11. Katz, A. and W. E. Becker. 1999. Technology and the teaching of economics to undergraduates. Journal of Economic Education (Summer): 194-199.

12. Kilpatrick, T. L. 1998. Will books become dumb medium. Library Software Review 17 (September): 208.

13. Knoedler, J.T. and D.A. Underwood 2003. Teaching the Principles of economics: A proposal for a multiparadigmatic approach. Journal of Economic Issues (September): 697-725.

14. Kydd, C. T. 1999. The effect of multimedia presentations on learning operations management: perception or reality?. New England Decision Sciences Institute Conference, Proceedings (March): 32-34.

15. Manning, L. 1996. Economics on Internet: Electronic Mail in the Classroom. Journal of Economic Education (Summer): 201-204.

16. McGrath, B. 1998. Partners in learning: twelve ways technology changes the teacher-student relationship. T.H.E Journal (April): 58-61.

17. Parks, R. P. 1999. Macro principles, PowerPoint, and the internet: four years of the good, the bad and the ugly. Journal of Economic Education (Summer): 200-224.

18. Porter, T. and T. Riley. 1992. Cai in economics: what happened to the revolution? Journal of Economic Education (Fall):374-378.

19. Raymond III, F.B. 2000. Delivering distance-based education through technology: A pioneer's experience. Campus-wide Information Systems: 49-53.

20. Simkins, S. P. 1999. Promoting active-student learning using the world wide web in economics courses. Journal of Economic Education (Summer): 278-291.

21. Sosin, K; Blecha, B., Agarwal, R., Bartlett, R., and J. Daniel 2004. Efficiency in the Use of Technology in Economics Education: Some Preliminary Results. The American Economic Review (May): 253-258.

22. Stone, L. L. 1999. Multimedia instruction methods. Journal of Economic Education (Summer): 265-275.

23. Wellner, A. 1999. Get Ready for Generation. Training 36 (February): 42-48. 